\title{
Perancangan Sistem Pemantauan Suhu dan Kelembaban pada Proses Dekomposisi Pupuk Kompos berbasis IoT
}

\author{
Farida Hardyanti ${ }^{1}$, Pramudi Utomo ${ }^{2}$ \\ 1,2Program Studi Teknik Elektronika Fakultas Teknik Universitas Negeri Yogyakarta \\ E-mail: faridahardyan@gmail.com
}

\begin{abstract}
The problem that often occurs in making compost is the level of fertilizer maturity that is not perfect. This is caused by humidity and temperature in the unstable manufacturing process. This article aims to develop a system capable of controlling temperature and humidity as well as monitor changes in the process of compost decomposition wirelessly and describe the results of testing the system. This research uses a development method with several stages, namely: problem identification and needs analysis, design, implementation, and testing. The results show that: (1) a temperature and humidity monitoring system is realized to monitor and regulate the process of making IoT-based compost by utilizing DHT-22 sensor input as a temperature and humidity detector and sensor to detect the $\mathrm{pH}$ content of compost processed using Wemos D1 mini. Output data that has been obtained will be sent to the Android smartphone application and in the form of a relay that will activate the heater and cooler as a temperature stabilizer; and (2) the test results show that performance is appropriate, which by manual means has the advantages of: (a) more efficient 2 to 4 weeks; and (b) has automatic and manual control.
\end{abstract}

Keywords: Compost, DHT-22, pH sensor, Internet of Things, Blynk

\begin{abstract}
ABSTRAK
Masalah yang sering terjadi dalam pembuatan pupuk kompos adalah tingkat kematangan pupuk yang tidak sempurna. Hal tersebut disebabkan oleh kelembaban dan suhu dalam proses pembuatan yang tidak stabil. Artikel ini bertujuan untuk mengembangkan sistem yang mampu mengendalikan suhu dan kelembaban serta memantau perubahan proses dekomposisi pupuk kompos secara nirkabel dan mendeskripsikan hasil pengujian sistem tersebut. Penelitian ini menggunakan metode pengembangan dengan beberapa tahapan, yaitu: identifikasi masalah dan analisis kebutuhan, perancangan, implementasi, dan pengujian. Hasil menunjukkan bahwa: (1) sistem pemantauan suhu dan kelembaban direalisasikan untuk memantau serta mengatur proses pembuatan pupuk kompos berbasis IoT dengan memanfaatkan input sensor DHT-22 sebagai pendeteksi suhu dan kelembaban dan sensor untuk mendeteksi kandungan pH kompos yang diproses menggunakan Wemos D1 mini. Output data yang telah diperoleh akan dikirim ke aplikasi smartphone android dan berupa relay yang akan mengaktifkan pemanas dan pendingin sebagai penyetabil suhu; dan (2) hasil pengujian menunjukkan kinerja yang sesuai, dimana dengan cara manual memiliki keunggulan yaitu: (a) lebih efisien 2 sampai dengan 4 minggu; dan (b) memiliki kontrol otomatis dan manual.
\end{abstract}

Kata kunci: Pupuk Kompos, DHT-22, sensor pH, Internet of Things, Blnyk

\section{PENDAHULUAN}

Produktivitas lahan pertanian yang ada setiap tahunnya mengalami penurunan karena penggunaan pupuk kimia. Pemakaian pupuk kimia telah terbukti merusak tanah dan lingkungan sehingga dianjurkan untuk menggunakan pupuk organik [1], [2]. Manfaat dari penggunaan pupuk organik adalah dapat memperbaiki sifat fisik, kimia dan biologi tanah. Penggunaan pupuk organik akan menghasilkan produk pertanian organik yang lebih menyehatkan daripada pupuk kimia. Saat ini penggunaan pupuk organik oleh petani padi mulai meningkat, sehingga ketersediaan pupuk tersebut perlu mendapat perhatian. 
Pupuk organik adalah pupuk yang tersusun dari pelapukan sisa tanaman, hewan dan manusia baik dalam bentuk padat maupun cair, yang dapat bersumber dari sampah organik, daun hijau dan kering, sisa panen seperti jerami maupun sekam padi dan limbah ternak. Pemanfaatan jerami dan sekam padi setelah pasca panen menjadi peluang yang cukup besar bagi petani untuk menambah nilai jerami dan sekam padi. Pupuk organik atau kompos umumnya dihasilkan dari proses pengomposan. Proses penguraian bahan-bahan organik secara biologis, khususnya oleh mikroba-mikroba yang dapat memanfaatkan bahan organik sebagai sumber energi disebut sebagai pengomposan.

Proses pembuatan pupuk kompos yang dilakukan secara alami memerlukan waktu kurang lebih tiga bulan. Hal ini dapat dilakukan dengan membuat campuran bahan yang seimbang, pemberian air secukupnya, mengatur aerasi dan menambah aktivator [3] Kelembaban, suhu dan $\mathrm{pH}$ merupakan beberapa faktor yang mempengaruhi proses pembuatan pupuk [4]. Dalam pembuatan pupuk kompos masalah yang sering terjadi adalah tingkat kematangan pupuk yang tidak sempurna. Hal tersebut disebabkan oleh tingkat kelembaban dan suhu dalam proses pembuatan tidak stabil. Pada metabolisme mikroba, kelembaban harus dijaga pada kisaran $40 \%$ hingga $60 \%$. Terjadi peningkatan suhu yang cepat antara $35^{\circ} \mathrm{C}$ sampai dengan $60^{\circ} \mathrm{C}$ dalam tumpukan kompos [4]. Pembuatan pupuk kompos yang belum matang secara keseluruhan dapat menghambat pertumbuhan tanaman dikarenakan kekurangan nitrogen yang tersedia. Berpijak dari uraian tersebut, maka diperlukan monitoring kelembaban dan suhu pada proses pengomposan. Artikel ini bertujuan untuk mengembangkan sistem yang mampu mengendalikan suhu dan kelembaban serta memantau perubahan proses dekomposisi pupuk kompos secara nirkabel dan mendeskripsikan hasil pengujian sistem tersebut.

Sistem monitoring suhu dan kelembaban pernah dibuat sebelumnya, namun implementasi alat tersebut berfokus pada suhu dan kelembaban sebagai parameter utama. Pada proyek tersebut perancangan sistem menggunakan sensor suhu DS18B20 dan kelembaban tanah DFRobots V2 (Soil Moisture) [5]. Sistem monitoring secara realtime plan pada pembuatan pupuk organik telah dikembangkan menggunakan mikrokontroler sebagai pengendali, sensor kelembaban DHT22 [6]. Salah satu sensor pH adalah sensor E201-C [7]. Perangkat pendeteksi suhu dan kelembaban pada proses pembuatan pupuk organic sebelumnya menggunakan sensor DHT11 [4]. Terdapat pengembangan monitoring $\mathrm{pH}$ secara wireless akan tetapi digunakan untuk tanaman kentang aeroponik [8]. Automatisasi berbasis Internet of Things (IoT) telah diterapkan untuk mengendalikan kompor listrik menggunakan smartphone android [9].

Teknologi pertanian saat ini perlu memanfaatkan teknologi internet melalui aplikasi seluler, misalnya dalam pengendalian kondisi $\mathrm{pH}$ dan suhu untuk mendukung sistem industry 4.0 [10]. Implementasi IoT dengan android semakin dimudahkan dengan adanya Blynk. Blynk merupakan platform IoT yang dapat diaplikasikan pada aplikasi seluler, private clouds, device management, data analytics, dan machine learning [11]. Blynk dirancang untuk IoT yang dapat mengontrol perangkat keras dari jarak jauh, dapat menampilkan data sensor, dapat menyimpan data, melakukan vizualisasi dan melakukan banyak hal bermanfaat lainnya. Terdapat tiga komponen utama dalam platform tersebut, yaitu: (1) Blynk App sebagai antarmuka; (2) Blynk Server yang bertanggung jawab atas semua komunikasi antara smartphone dan perangkat keras; dan (3) Blynk Libraries [12]. Adapun perbedaan sistem yang dibuat pada alat ini dengan alat sebelumnya yaitu: (1) Penambahan sensor $\mathrm{pH}$ guna mendeteksi tingkat kematangan pada pupuk kompos; (2) Pemilihan sensor kelembaban tanah dan suhu menggunakan DHT-22 yang mempunyai nilai akurasi tinggi dan presisi dalam pengukuran; dan (3) Penggunaan Wemos D1 Mini sebagai mikrokontrolernya dan sebagai modul wifi yang akan menghubungkan sistem dengan smartphone pengguna. 


\section{METODE}

Pengembangan perangkat dalam penelitian ini melalui beberapa tahapan yaitu: (1) identifikasi masalah dan analisis kebutuhan; (2) perancangan perangkat keras dan perangkat lunak; (3) pembuatan perangkat; dan 4) pengujian. Seperti yang telah dijelaskan sebelumnya permasalahan yang melatar belakangi pembuatan sistem ini adalah proses pembuatan pupuk organik yang membutuhkan waktu yang cukup lama. Hal tersebut disebabkan oleh tingkat kelembaban dan suhu yang tidak stabil, sehingga mengakibatkan kematangan pupuk yang tidak sempurna serta lama.

Tabel 1. Komponen-komponen Utama Sistem

\begin{tabular}{|c|c|c|}
\hline No. & Komponen & Fungsi \\
\hline 1 & Ember & Sebagai tempat dekompoisi pupul \\
\hline 2 & Box panel & $\begin{array}{l}\text { Sebagai tempat komponen } \\
\text { elektronik }\end{array}$ \\
\hline 3 & $\begin{array}{l}\text { Sensor } \\
\text { DHT-22 }\end{array}$ & $\begin{array}{l}\text { Sebagai pendeteksi suhu dan } \\
\text { kelembaban pada proses } \\
\text { pembuatan pupuk kompos }\end{array}$ \\
\hline 4 & Sensor pH & $\begin{array}{l}\text { Sebagai pengukur kandungan } \mathrm{pH} \\
\text { kompos, yang mana sensor } \mathrm{pH} \text { ini } \\
\text { nanti akan mengindikasikan sudah } \\
\text { matangnya sebuah kompos }\end{array}$ \\
\hline 5 & $\begin{array}{l}\text { Wemos D1 } \\
\text { mini }\end{array}$ & $\begin{array}{l}\text { Sebagai mikrokontroler yang akan } \\
\text { mengolah data dari sensor sebagai } \\
\text { input hingga dapat diteruskan ke } \\
\text { proses output serta untuk } \\
\text { mengintregrasikan sistem } \\
\text { pemantuan ke smartphone pembuat } \\
\text { kompos }\end{array}$ \\
\hline 6 & Relay & $\begin{array}{l}\text { Sebagai saklar yang akan } \\
\text { menyalakan maupun mematikan } \\
\text { pemanas ketika mencapai suhu } \\
\text { yang dikehendaki. }\end{array}$ \\
\hline 7 & Pemanas & $\begin{array}{l}\text { Untuk menaikkan suhu apabila } \\
\text { suhu belum memenuhi batas yang } \\
\text { dikehendaki. }\end{array}$ \\
\hline 8 & Fan & $\begin{array}{l}\text { Untuk menurunkan suhu apabila } \\
\text { suhu di atas batas yang } \\
\text { dikehendaki. }\end{array}$ \\
\hline 9 & $\begin{array}{l}\text { Aplikasi } \\
\text { Blynk }\end{array}$ & $\begin{array}{l}\text { Untuk menampilkan nilai hasil } \\
\text { pemantauan }\end{array}$ \\
\hline
\end{tabular}

Analisis kebutuhan pada sistem ini menjelaskan mengenai rincian kebutuhan alat dan bahan guna menunjang pembuatan sistem pemantauan suhu dan kelembaban pada proses dekomposisi pupuk kompos. Analisis dilakukan agar tercapainya komponen yang tepat digunakan dalam perancangan. Pada Tabel 1 berikut dapat dilihat komponen- komponen yang akan digunakan yang terdiri dari kebutuhan hardware dan software. Hardware terdiri atas: (1) mekanik berupa boks panel dan ember; serta (2) elektronik berupa Sensor DHT-22, relay, Sensor $\mathrm{pH}$, Pemanas, Wemos D1 mini dan fan. Software yang digunakan adalah Arduino IDE dan Blnyk. Perancangan sistem dibuat secara garis besar sesuai dengan blok diagram pada Gambar 1.

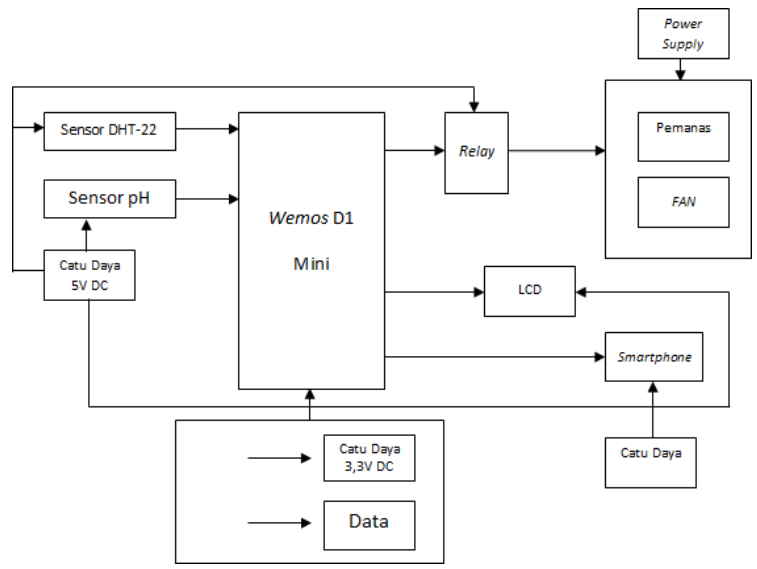

Gambar 1. Blok Diagram Sistem Pemantauan Suhu dan Kelembaban

Gambar 1 merupakan blok diagram sistem kinerja alat yang akan dibuat. Dari blok diagram diketahui terdapat perbedaan dengan metode manual yaitu terdapat sensor yang menghasilkan informasi kelembaban dan suhu, pemrosesan oleh Wemos D1 mini dan output berupa relay yang akan mengaktifkan pemanas dan fan sesuai kebutuhan. Alat ini terbagi menjadi 3 bagian yaitu input, proses, dan output. Masukan atau input dari alat ini adalah kelembaban, suhu dan kandungan $\mathrm{pH}$ pada pupuk. Sensor yang digunakan adalah sensor $\mathrm{pH}$ dan DHT-22. Sensor $\mathrm{pH}$ berguna untuk mengukur kandungan $\mathrm{pH}$ dari pupuk, sedangkan DHT-22 berguna untuk mengukur kelembaban dan suhu. Kemudian data yang diperoleh sensor akan masuk pada bagian proses. Bagian proses menggunakan mikrokontroler Wemos D1 mini. Wemos D1 mini akan menghubungkan hasil 
pemantauan dari sistem kepada smartphone pembuat yang nantinya akan memberikan perintah pada relay untuk mengaktifkan pemanas ataupun mengaktifkan fan hingga mencapai suhu tertentu. Tahap output adalah menyalakan pemanas untuk menaikkan suhu hingga mencapai batas yang telah ditentukan begitu juga dengan fan apabila suhu di atas batas yang ditentukan. Proses tersebut akan dikirimkan kepada smartphone pembuat, hingga sensor $\mathrm{pH}$ telah menunjukkan hasil yang ditentukan yang mengindikasikan bahwa pupuk telah matang. Cara kerja sistem dijelaskan sesuai gambar flowchart pada Gambar 2.

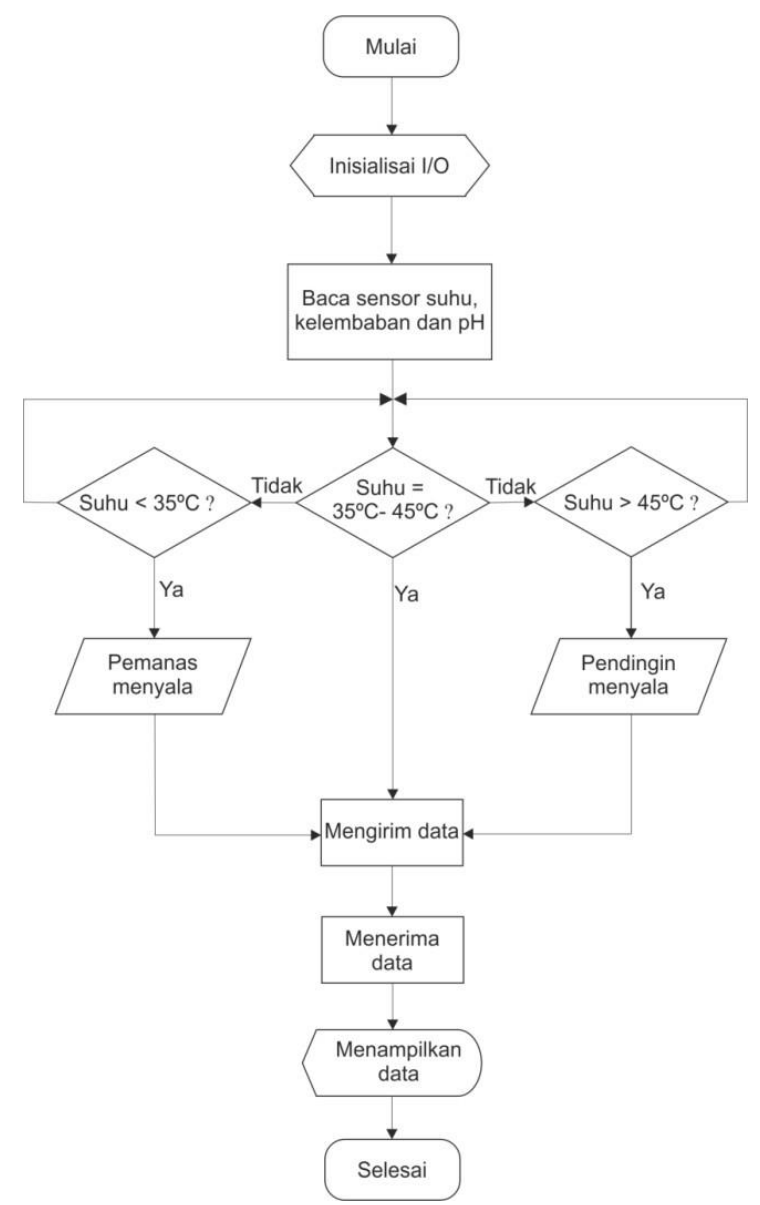

Gambar 2. Flowchart Sistem Pemantauan

Cara kerja dari sistem adalah saat program sudah mulai dijalankan maka yang pertama kali yaitu menginisialisasi input ouput. Sensor DHT-22 akan mulai mendeteksi suhu dan kelembaban pada ruang pemngomposan dan sensor $\mathrm{pH}$ akan mulai mendeteksi kandungan $\mathrm{pH}$ pada kompos. Data yang diterima akan diteruskan dan diproses oleh wemos D1 mini. Selanjutkan data yang telah diproses tersebut akan ditampilkan pada LCD serta ditampilkan pada android melalui koneksi wifi. Jika suhu kurang dari $35^{\circ} \mathrm{C}$ maka hair dryer (pemanas) akan menyala, sedangkan jika suhunya lebih dari $45^{\circ} \mathrm{C}$ maka fan (pendingin) akan menyala otomatis. Kemudian data akan ditampilkan kembali pada LCD dan android.

\section{HASIL DAN PEMBAHASAN}

Implementasi pembuatan alat yaitu dilakukan dengan mengintregasikan semua komponen yang dibutuhkan. Langkah pembuatan pertama adalah mempersiapkan alat dan bahan untuk membuat prototype. Alat dan bahan yang digunakan untuk membuat prototype dari sistem pemantauan suhu dan kelembaban pada proses dekomposisi pupuk kompos sesuai identifikasi kebutuhan. Alat dan bahan tersebut akan dirangkai sesuai dengan desain mekanik maupun rangkaian elektroniknya. Langkah berikutnya membuat mekanik sesuai dengan desain yang telah dibuat. Desain hardware dibuat menggunakan software CorelDraw X7. Hardware dan software disesuaikan dengan kebutuhan dan variabel sehingga didapatkan hasil yang optimal. Gambar 3(a) dan Gambar 3(b) merupakan desain hardware.

Langkah ketiga adalah membuat perangkat keras yang terdiri dari sensor DHT-22, sensor $\mathrm{pH}$, Wemos D1 mini, pemanas, fan, dan relay. Semua komponen yang ada dirakit pada papan PCB yang telah dibuat sesuai dengan skematik rangkaian pada Gambar 4. Komponen yang telah dirakit kemudian dimasukkan ke dalam box panel, agar terhindar dari gangguangangguan fisik yang dapat mempengaruhi kinerja komponen. Tahapan keempat adalah membuat perangkat lunak atau coding dari proses kerja sistem alat. Coding tersebut adalah program yang berisi perintah untuk melakukan pengendalian ataupun pembacaan nilai sensor. 
Pembuatan program pada wemos D1 mini menggunakan Arduino IDE dengan Bahasa C.

Wemos D1 mini memiliki pin analog dan digital yang digunakan sebagai input maupun output.

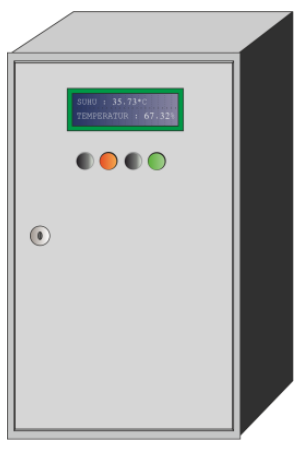

(a)

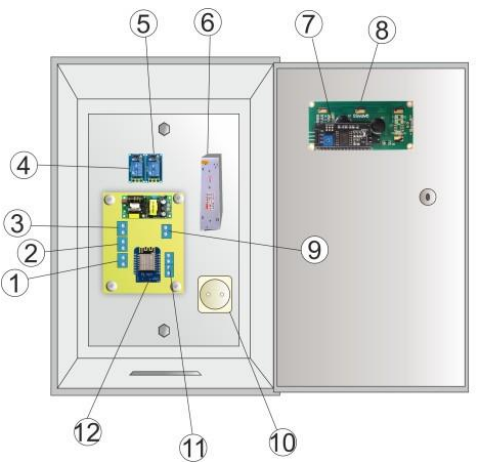

(b)
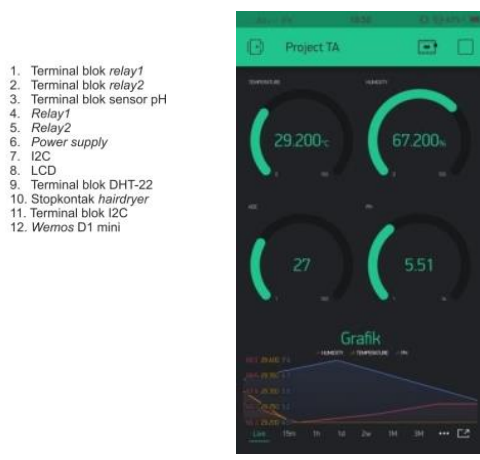

(c)

Gambar 3. (a) Desain Hardware Sistem, (b) Keterangan Desain Hardware Sistem, (c) Desain Software Sistem

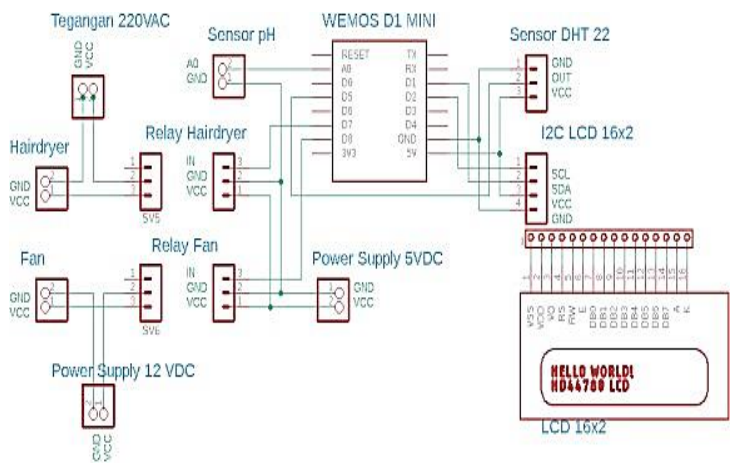

Gambar 4. Skematik Rangkaian Sistem

Tahapan kelima adalah membuat aplikasi yang dapat memantau sistem dengan android. Aplikasi yang dibuat yaitu dengan menggunakan Blynk yang telah didownload dan diinstal pada android. Pinout yang digunakan disamakan dengan program pada Arduino IDE sehingga nantinya dapat terkoneksi melalui wifi. Gambar 3(c) merupakan desain software.

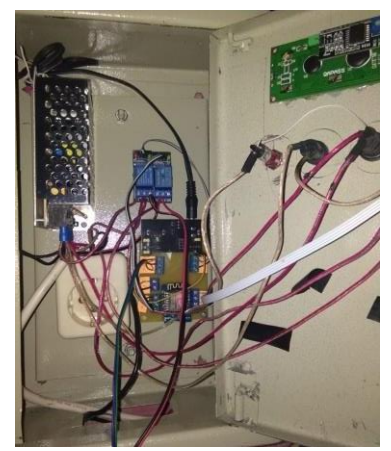

(a)

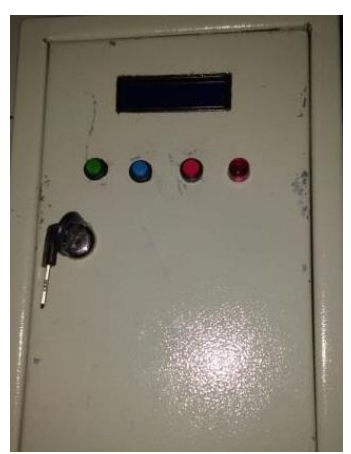

(b)
Gambar 5. (a) Instalasi Elektronik pada Boks Panel (b) Boks Panel Sistem Pemantauan
Setelah perancangan dilakukan maka dilanjutkan dengan implementasi. Box panel yang digunakan berukuran 20x30x12 cm. Pada permukaan box panel melekat LCD sebagai display dari hasil monitoring dan push button serta LED sebagai kontrol manual beserta indikatornya. Komponen elektronik yang telah dirangkai dimasukkan ke dalam box panel seperti pada Gambar 5(a), sehingga komponenkomponen tersebut terhindar dari gangguangangguan fisik yang dapat mempengaruhi kinerja komponen. Gambar 5(b) merupakan gambar boks panel produk.

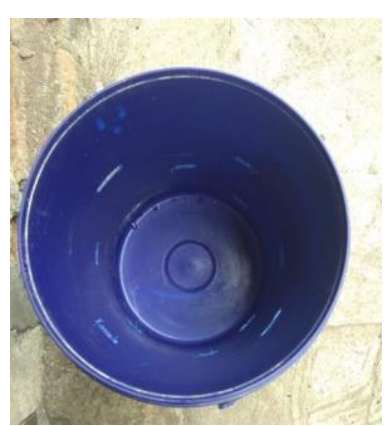

(a)

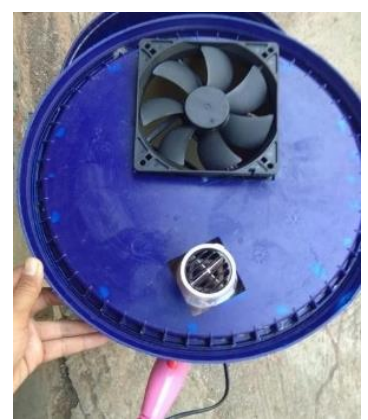

(b)
Gambar 6. (a) Tempat Pembuatan Kompos, (b) Tutup Ember yang Telah Dimodifikasi

Tempat pengomposan yang digunakan yaitu ember berdiameter $27 \mathrm{~cm}$ dan tinggi $40 \mathrm{~cm}$, yang dapat menampung kurang lebih $3 \mathrm{~kg}$ bahan mentah kompos. Ember yang terlihat pada Gambar 6(a) dan Gambar 6(b) dilubangi pada bagian sisinya sebagai fentilasi udara, dan 
dilubangi pada permukaannya/tutupnya sebagai tempat diletakkannya pendingin dan pemanas. Pembuatan tempat pengomposan pada ember dilakukan dengan maksud agar memudahkan pengujian awal sebelum direalisasikan pada tempat yang lebih besar seperti tong atapun bak yang besar.

Setelah rancangan diimplemetasikan, maka tahapan selanjutnya adalah pengujian. Pengujian sistem pemantauan suhu dan kelembaban pada proses dekomposisi pupuk kompos bertujuan untuk mengetahui apakah kinerja sistem sudah sesuai dengan yang diharapkan ataukah belum, baik software maupun hardware. Ada dua pengujian yang dilakukan yaitu: 1) pengujian awal/penyiapan kompos; dan 2) pengujian sistem monitoring pengomposan. Pengujian awal yaitu proses penyiapan kompos mulai dari penyiapan bahanbahan hingga proses pembuatan kompos. Bahan baku untuk pembuatan kompos ini terdiri dari $80 \%$ bahan organik, $10 \%$ pupuk kandang, dan $10 \%$ abu. Pengujian sistem monitoirng pengomposan terdiri dari dua langkah yaitu: 1) Uji fungsional yang dilakukan dengan menguji fungsi tiap komponen yang digunakan dengan tujuan untuk mengetahui apakah setiap komponen berfungsi dengan baik atau tidak; 2) Uji unjuk kerja dilakukan dengan tujuan untuk mengetahui apakah alat sesuai dengan standar pengukuran suhu dan kelembaban serta untuk mengetahui apakah alaat sudah bekerja sesuai yang diharapkan atau belum.

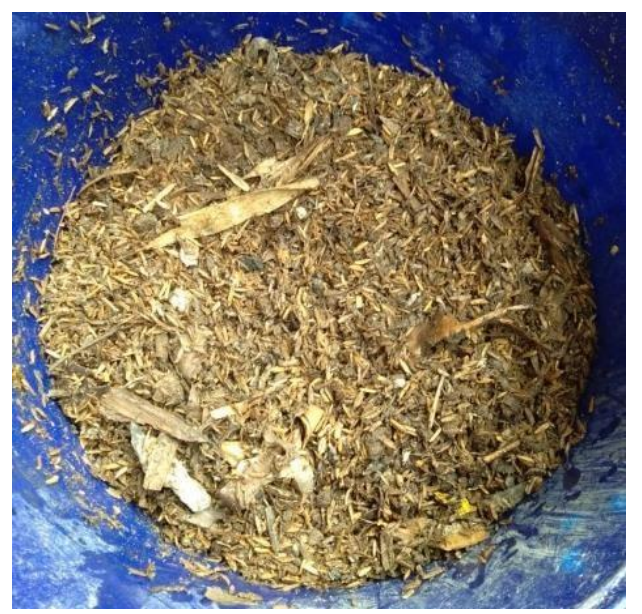

Gambar 7. Kompos Yang Belum Terdekomposisi
Untuk pengujian awal, pembuatan kompos berlangsung selama hampir dua bulan dengan hasil yang belum begitu sempurna. Waktu dua bulan tersebut berdasarkan pengalaman nyata yang dilakukan pada tanggal 2 Februari 2019 hingga 4 Mei 2019. Pada Gambar 7 masih terlihat bahan yang belum terdekomposisi, hal ini dikarenakan suhu dan kelembaban yang tidak teratur atau di luar batas yang dikehendaki. Selain itu tidak adanya oksigen yang mengisi ruangan karena tertutup rapat.

Berdasarkan tahapan pengujian sistem monitoring pengomposan yang telah dilaksanakan maka dapat disimpulkan bahwa sistem yang dirancang bekerja sebagaimana yang diharapkan dan sesuai dengan fungsinya. Pada pengukuran terdapat beberapa perbedaan hasil dari hasil pengukuran dengan teori atau datasheet komponen. Perbedaan hasil tersebut disebabkan oleh beberapa faktor diantaranya yaitu toleransi nilai komponen dari pabrik, kondisi alat ukur yang kurang bagus dan kurang telitinya dalam pengukuran.

Data hasil pengujian sensor dengan melakukan perbandingan pembacaan suhu pada sensor DHT-22 dengan termometer dan pembacaan kelembaban pada sensor DHT-22 dengan soil moisture. Berikut perbandingan pembacaan suhu dan kelembaban dapat dilihat dalam bentuk grafik pada Gambar 8(a) dan Gambar 8(b). Hasil perbandingan suhu didapatkan rata-rata error sebesar $1,30^{\circ} \mathrm{C}$ sedangkan rata-rata error kelembaban yang dihasilkan pada perbandingan pembacaan tersebut adalah $4,98 \%$. Sesuai dengan teori yang ada yaitu sensor DHT-22 memiliki akurasi suhu $\pm 0,5^{\circ} \mathrm{C}$, sedangkan pada pengujian tercatat selisih perbedaan nilai sensor dengan alat ukur yaitu mulai dari 0,2 sampai 0,5 . Dan nilai akurasi kelembaban $\pm 2 \%(\max \pm 5 \%)$, sedangkan selisih pengukuran yaitu dari $2,0 \%$ hingga $4,7 \%$. Dari hasil pengujian dan perhitungan pada perbandingan pengukuran tersebut dapat dikatakan bahwa pembacaan suhu dan kelembaban hampir mendekati sama dengan pembacaan menggunakan termometer dan soil 
moisture yang digunakan sebagai pembanding dan tidak melebihi batas akurasi. Hasil pengujian sensor $\mathrm{pH}$ dapat dilihat pada Gambar 8(c), yaitu dengan melakukan perbandingan pembacaan $\mathrm{pH}$ pada sensor $\mathrm{pH}$ dengan $\mathrm{pH}$ meter. Hasil pengujian perbandingan suhu didapatkan selisih nilai pengukuran dengan perhitungan adalah dari
0,01 sampai 0,1 . Hasil tersebut menunjukkan bahwa sensor telah sesuai dengan teori yang ada yaitu sensor $\mathrm{pH}$ memiliki akurasi sebesar 0,1 . Dari pengujian tersebut dapat dikatakan bahwa pembacaan $\mathrm{pH}$ hampir mendekati sama dengan pembacaan alat ukur $\mathrm{pH}$ meter.

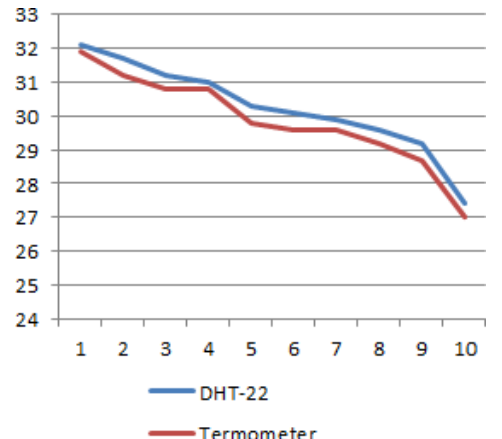

(a)

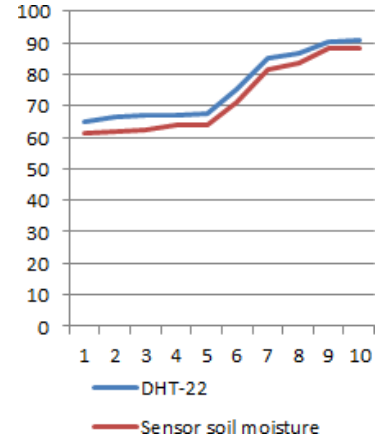

(b)

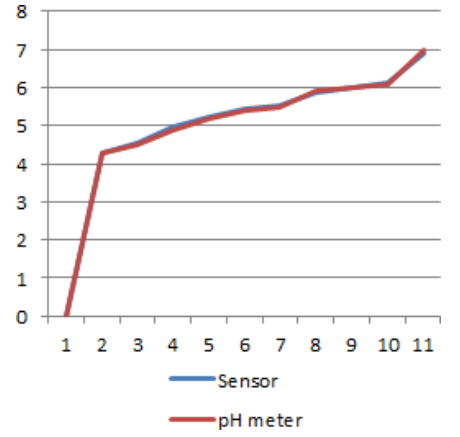

(c)

Gambar 8(a) Grafik Perbandingan Suhu (DHT-22 dan Termometer), 8(b) Grafik Perbandingan Kelembaban (DHT-22 dan Sensor Soil Moisture), (c) Grafik Perbandingan pH (Sensor pH Tanah dan pH Meter)

Berdasarkan hasil pengujian pada Tabel 2 wemos yang digunakan telah berjalan dengan baik, hal ini dapat dilihat dari konektivitas wifinya yang langsung terhubung. Selain itu, seluruh pin yang digunakan juga baik karena mampu memproses input menjadi output.

Tabel 2. Pengujian Wemos D1 Mini

\begin{tabular}{clc}
\hline No. & \multicolumn{1}{c}{ Pengujian } & Hasil \\
\hline 1 & Tegangan & Baik \\
& Wemos D1 mini Spesifikasi & \\
& pada datasheet: 3.3 V & \\
& $\begin{array}{l}\text { Pengukurang dengan } \\
\text { multimeter:3.23 V }\end{array}$ \\
2 & Konektivitas wifi & \\
\hline
\end{tabular}

Pada Tabel 3 dapat dilihat hasil pengujian relay yang telah dilakukan. Hasil pengujian tersebut menunjukkan relay dapat bekerja dengan baik. Pengujian ini untuk mengetahui berfungsi atau tidaknya koil relay dan kontak relay. Pengujian dilakukan dengan memasukkan perintah untuk menyalakan relay. Hasil yang diperoleh yaitu relayl dapat aktif/ON ketika suhu kurang dari $35^{\circ} \mathrm{C}$ dan relay 2 tidak aktif/OFF, sedangkan relay2 dapat aktif/ON ketika suhu lebih dari $45^{\circ} \mathrm{C}$ dan relayl tidak aktif/OFF.
Tabel 3. Pengujian Relay1 dan Relay2

\begin{tabular}{cccc}
\hline No. & Suhu & Kondisi relayl & Kondisi relay2 \\
\hline 1 & $29^{\circ} \mathrm{C}$ & ON & OFF \\
2 & $311^{\circ} \mathrm{C}$ & ON & OFF \\
3 & $36^{\circ} \mathrm{C}$ & OFF & ON \\
4 & $37^{\circ} \mathrm{C}$ & OFF & ON \\
5 & $40^{\circ} \mathrm{C}$ & OFF & ON \\
\hline
\end{tabular}

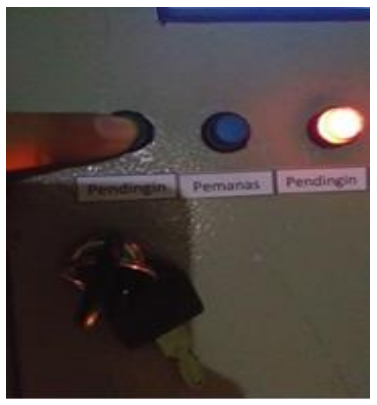

(a)

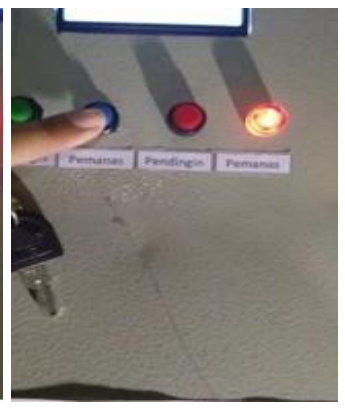

(b)
Gambar 9. Pengujian Push Button dan LED Indikator: a) Pendingin; b) Pemanas

Push button dan LED indikator terhubung paralel. Terdapat dua push button dan dua LED indikator. Satu pasang push button dan LED sebagai kontrol manual pemanas dan satunya sebagai kontrol manual pendingin. Pada Gambar 9 menunjukkan bahwa push button dan LED dapat bekerja dengan baik. Ketika kita tekan push button pemanas maka hair dryer akan hidup dan LED indikatornya akan menyala, 
begitu juga satunya ketika kita tekan push button pendingin maka fan akan hidup dan LED indikatornya akan menyala.

Sistem ini menggunakan dua sumber tegangan yang berbeda yaitu $220 \mathrm{~V}$ AC sebagai catu daya hair dryer (pemanas) dan $12 \mathrm{~V}$ DC sebagai catu daya fan (pendingin). Pengujian dilakukan dengan mengukur ouput sumber tegangan menggunakan multimeter. Selanjutnya pengujian juga dilakukan untuk memastikan bahwa hubungan paralel dari sumber tegangan sudah benar-benar berfungsi dengan baik. Hasil yang didapatkan yaitu output tegangan telah bekerja sesuai dengan semestinya baik sumber tegangan $220 \mathrm{~V}$ AC maupun $12 \mathrm{~V}$ DC.

Pembacaan data sensor divisualisasikan dalam dua device yaitu menggunakan LCD yang telah dipasang pada sistem hardware dan menggunakan aplikasi Blynk pada android. Hasil pengujian data sensor dapat dilihat pada Tabel 4, yaitu perbandingan antara nilai yang ditampilkan pada LCD dan pada Blynk. Dari hasil tersebut nilai dari kedua device adalah sama, sehingga pembacaan data sensor telah sesuai yang diharapakan.

Tabel 4. Pembacaan Data Sensor

\begin{tabular}{|c|c|c|c|}
\hline No. & Parameter & LCD & Blynk \\
\hline 1 & Suhu $\left({ }^{\circ} \mathrm{C}\right)$ & 29,30 & 29,300 \\
\hline 2 & & 30,10 & 30,100 \\
\hline 3 & Kelembaban (\%) & 67,40 & 67,400 \\
\hline 4 & & 66,90 & 66,900 \\
\hline 5 & $\mathrm{pH}$ & 6,14 & 6,14 \\
\hline 6 & & 5,45 & 5,45 \\
\hline
\end{tabular}

Hasil pengujian alat secara keseluruhan menunjukkan alat dapat bekerja sesuai dengan perancangan prinsip kerja alat. Apabila suhu dibawah nilai standar maka akan menyalakan hair dryer sedangkan apabila suhu diatas standar maka akan menyalakan fan. Sesuai dengan pengalaman nyata, telah dilakukan implementasi alat pada tanggal 12 Mei 2019 hingga 22 Juni 2019, hasil yang diperoleh yaitu pupuk kompos. Dalam waktu kurang lebih enam minggu tersebut pupuk kompos yang dibuat dengan menggunakan sistem monitoring telah terdekomposisi, dapat dilihat pada Gambar 10.
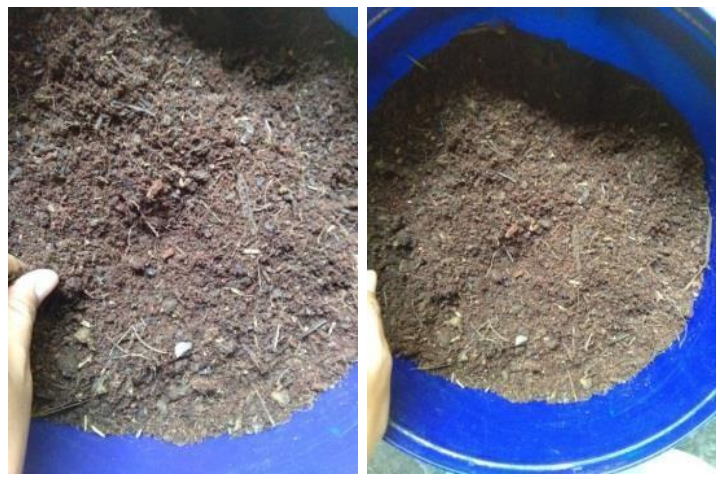

Gambar 10. Hasil Pengomposan

Waktu yang digunakan untuk membuat pupuk kompos dari bahan mentah hingga menjadi kompos menggunakan sistem monitoring lebih efektif 2 sampai dengan 4 minggu dibandingkan dengan cara manual, sehingga dapat dikatakan bahwa alat ini lebih efisien waktu dalam membuat pupuk kompos. Selain dari segi waktu, perbandingan efektivitas alat yang dikembangkan juga dapat dilihat dari keunggulan yang ada seperti kontrol otomatis dan manual. Hasil pengujian ini menunjukkan cara pembuatan kompos menggunakan teknologi dengan alat yang dikembangkan pada proyek akhir ini dapat mempercepat pembuatan kompos.

Berdasarkan hasil pengujian alat terdapat saran-saran untuk penelitian pengembangan perangkat yang serupa selanjutnya, yaitu: (1) Pengkabelan pada perakitan komponen harus lebih dirapikan lagi agar terhindar dari korsleting atau hal-hal yang tidak diinginkan lainnya; (2) Pengembangan dan penyempurnaan tampilan Blynk perlu dioptimalkan kembali supaya tampilan lebih menarik; (3) Pengembangan alat perlu ditambahkan sistem pengendali jarak jauh agar pembuat kompos dapat mengendalikan pemanas ataupun pendingin melalui android apabila suhu masih belum sesuai dengan yang diharapkan. Hal tersebut mendukung rea industri 4.0 melalui pemanfaatan IoT [10]; dan (4) Penambahan sistem penyiraman otomatis apabila tingkat kelembaban belum mencapai ketentuan. Penyiraman otomatis dapat menurunkan kelembaban [13], [14]. 


\section{SIMPULAN}

Berdasarkan hasil yang diperoleh dari pengembangan dan pengujian sistem pemantuan proses pembuatan pupuk kompos dapat disimpulkan sebagai berikut: (1) Perancangan sistem pemantauan suhu dan kelembaban pada proses dekomposisi pupuk kompos dikembangkan menggunakan teknologi IoT yang menggabungkan hardware control dan software. Sistem ini terdiri dari tiga proses utama yaitu input, proses dan output. Input menggunakan sensor DHT-22 dan sensor $\mathrm{pH}$, data dari kedua sensor tersebut akan dikirim menuju wemos D1 mini untuk di proses. Pada wemos D1 mini juga, data akan di integrasikan ke android, sehingga output dari sistem ini berupa tampilan pada layar android. Selain itu output lain juga berupa relay yang akan mengaktifkan pemanas dan pendingin sebagai penyetabil suhu; dan (2) Hasil dari pengujian menunjukkan bahwa pembuatan kompos menggunakan sistem monitoring lebih efektif 2 sampai dengan 4 minggu dibandingkan dengan cara manual, dapat dikatakan bahwa alat ini lebih efisien waktu dalam membuat pupuk kompos. Selain dari segi waktu, perbandingan efektivitas alat yang dikembangkan juga dapat dilihat dari keunggulan yang ada seperti kontrol otomatis dan manual. Sistem pemantauan suhu dan kelembaban ini dapat dijalankan dengan menghubungkan sumber tegangan 220VAC ke sumber listrik PLN, selanjutnya menghidupkan hostpot pada android, kemudian membuka aplikasi Blynk pada android. Hasil pemantauan dapat dilihat pada LCD maupun pada aplikasi Blynk. Apabila ingin melakukan kontrol manual dapat menekan push button yang terdapat pada hardware.

\section{DAFTAR PUSTAKA}

[1] S. Umniyatie, D. Pramiadi, V. Henuhili, and D. Djuwanto, "Pembuatan pupuk organik menggunakan mikroba efektif," Inoteks, vol. 1, no. 3, pp. $142-146,2000$.
[2] S. Umniyatie, "Pembuatan Pupuk Organik Menggunakan Mikroba Efektif-4 (Effective Microorganisme-4)," 2014.

[3] Nyoman P., Aryantha, and Dkk, "Kompos," Pusat Penelitian Antar Universitas Ilmu Hayati LPPM-ITB. Dept. Biologi - FMIPA - ITB, 2010.

[4] S. A.S, R. I. Putri, and N. H, "Pendeteksi suhu dan kelembaban pada proses pembuatan pupuk organik," J. ELTEK, vol. 13, no. 1, pp. 1-10, 2015.

[5] V. D. K, Z. Zulhelmi, and M. Syaryadhi, "Monitoring Suhu dan Kelembaban Menggunakan Mikrokontroler ATMega328 pada Proses Dekomposisi Pupuk Kompos," Kitektro, vol. 2, no. 3, pp. 91-98, 2017.

[6] A. Mardiyanto, A. Akhyar, and Suherman, "Rancang bangun sistem monitoring plan pengontrol proses secara realtime pada pembuatan pupuk organik," in Prosiding Seminar Nasional Teknologi IV: Inovasi dan Aplikasi di Lingkungan Tropis, 2017, pp. F10 F20.

[7] R. D. Rima, W. Wildian, and N. Firmawati, "Rancang Bangun Prototipe Sistem Kontrol pH Tanah Untuk Tanaman Bawang Merah Menggunakan Sensor E201-C," J. Fis. Unand, vol. 7, no. 1, pp. 63-68, 2018.

[8] A. W. Wicaksono, E. R. Widasari, and F. Utaminingrum, "Implementasi Sistem Kontrol dan Monitoring $\mathrm{pH}$ pada Tanaman Kentang Aeroponik secara Wireless," JPTIIK (Jurnal Pengemb. Teknol. Inf. dan Ilmu Komputer), vol. 1, no. 5, pp. 386-398, 2017.

[9] Y. Yuliza and H. Pangaribuan, "Rancang bangun kompor listrik digital IoT," J. Teknol. Elektro, vol. 7, no. 3, pp. 187-192, 2016.

[10] S. Garsoni, "Menuju Sistem Industri 4.0 Pembangkitan Biogas dan Produksi Kompos," Bioindustri Pertanian, 2018. [Online]. Available: http://www.bioindustri.biz/2018/09/menujusistem-industri-40-pembangkitan.html.

[11]B. Inc, "We make Internet of Things simple for you," Blynk, 2019. [Online]. Available: https://blynk.io/.

[12] B. Inc, "Intro," Blynk, 2019. [Online]. Available: http://docs.blynk.cc/.

[13]M. Al Furqon, "Prototipe Sistem Penyiram Tanaman Otomatis berdasarkan Kelembaban Tanah berbasis Mikrokontroler," Universitas Syiah Kuala, 2017.

[14] Gunawan and M. Sari, "Rancang Bangun Alat Penyiram Tanaman Otomatis Menggunakan Sensor Kelembaban Tanah," J. Electr. Technol., vol. 3, no. 1, pp. 13-17, 2018. 